\title{
Serum Adiponectin Levels and Changes in Glucose Metabolism before and after Treatment for Thyroid Dysfunction
}

\author{
Didem Ozdemir, Selcuk Dagdelen and Aydan Usman
}

\begin{abstract}
Objective Adiponectin is an adipokine which is known to decrease in individuals associated with obesity and insulin resistance. In this study, we aimed to investigate the serum adiponectin levels and glucose metabolism in patients with thyroid dysfunction before and after treatment.

Methods Newly diagnosed overt hypothyroid $(n=20)$ and thyrotoxic $(n=23)$ patients and healthy controls $(\mathrm{n}=20)$ with a body mass index of $<30 \mathrm{~kg} / \mathrm{m}^{2}$ were evaluated prospectively. Patients with a known state of insulin resistance, including prediabetes and overt diabetes, and individuals with chronic diseases were excluded. Thyroid function and fasting plasma glucose (FPG), insulin, homeostatic model assessment (HOMA) insulin resistance (HOMA-IR) and HOMA-beta cell function (HOMA-beta), lipid and adiponectin levels were investigated in the basal state and after the restoration of euthyroidism.

Results The basal fasting FPG levels were lower in the hypothyroid patients than the control subjects ( $\mathrm{p}=$ 0.02 ) and similar between the thyrotoxic patients and control subjects ( $\mathrm{p}=0.127)$. The basal HOMA-beta levels were higher in the patients with hypothyroidism than in those with thyrotoxicosis $(p=0.015)$. Following the restoration of euthyroidism, the FPG levels significantly increased in the hypothyroid patients $(\mathrm{p}=0.002)$ and decreased in the thyrotoxic ( $\mathrm{p}=0.001)$ patients. The basal plasma adiponectin levels were $14.55 \pm 8.4 \mathrm{mcg} /$ $\mathrm{mL}, 13.79 \pm 9.13 \mathrm{mcg} / \mathrm{mL}$ and $11.68 \pm 6.0 \mathrm{mcg} / \mathrm{mL}$ in the hypothyroid and thyrotoxic patients and healthy controls, respectively $(\mathrm{p}=0.503)$. The adiponectin levels decreased significantly in the patients with hypothyroidism $(\mathrm{p}=0.047)$, whereas they did not change in the patients with thyrotoxicosis $(\mathrm{p}=0.770)$ after achieving euthyroidism.

Conclusion In this study, following the restoration of euthyroidism, the FPG levels increased in the hypothyroidism patients and decreased in the thyrotoxicosis patients, despite the lack of changes in the HOMA-IR and HOMA-beta levels. Meanwhile, the hypothyroid, thyrotoxic and euthyroid subjects had similar basal adiponectin levels, and a significant decrease in the adiponectin levels was observed after treatment for hypothyroidism, despite the absence of changes after treatment for thyrotoxicosis, indicating the need for further studies with a larger sample size.
\end{abstract}

Key words: hypothyroidism, thyrotoxicosis, adiponectin, insulin resistance

(Intern Med 54: 1849-1857, 2015)

(DOI: 10.2169/internalmedicine.54.0668)

\section{Introduction}

Adiponectin plays an important role in the regulation of a variety of processes, ranging from energy homeostasis, lipid metabolism and insulin sensitivity to inflammation and atherosclerosis (1). It is well established that the circulating adiponectin levels are reduced in patients with obesity and in- sulin resistance (2-5). In addition, an increased plasma adiponectin level is strongly and independently associated with a reduced risk of type 2 diabetes mellitus in healthy individuals (6), and it has been demonstrated that the adiponectin levels are lower in patients with atherogenic lipid profiles and high blood pressure $(7,8)$.

Thyroid dysfunction is usually associated with changes in body weight, appetite and thermogenesis. However, thyroid 
dysfunction-related changes in glucose and lipid metabolism are not well-defined. Although it is believed that thyrotoxicosis results in hepatic and peripheral insulin resistance (9), increased, decreased or normal insulin sensitivity has been reported in both thyrotoxic and hypothyroid patients in different studies (10-13).

The relationship between adiponectin and thyroid dysfunction, both having various effects on glucose and lipid metabolism, is controversial. It is known that thyrotropin (TSH) and thyroid hormone receptors are expressed in adipose tissue $(14,15)$. However, triiodothyronine (T3) was documented to not influence the expression of adiponectin in a study investigating the effects of various hormones on the regulation of the adiponectin gene expression in vitro (16). On the other hand, Cabanelas et al. recently showed that $\mathrm{T} 3$ is a potential inhibitor of the adiponectin mRNA expression, acting specifically in subcutaneous deposits in rats (17). Furthermore, a positive correlation between the adiponectin and serum free thyroxine (fT4) levels in healthy subjects has been described previously (18), although clinical studies investigating the serum adiponectin levels in patients with hypothyroidism and hyperthyroidism have reported conflicting results $(19,20)$. While various studies have demonstrated higher adiponectin levels in hyperthyroid or hypothyroid patients $(21,22)$, other reports have found no differences in the adiponectin levels in individuals with thyroid dysfunction $(23,24)$. Furthermore, it is not clear whether the possible changes in lipid and glucose metabolism observed after the restoration of euthyrodism can be explained by thyroid dysfunction-related adiponectin changes.

In this study, we aimed to evaluate the serum adiponectin levels before and after treatment in patients with thyroid dysfunction and investigate the possible role of adiponectin in thyroid dysfunction-related glucose and lipid metabolism changes.

\section{Materials and Methods}

\section{Subjects}

Patients diagnosed with overt thyrotoxicosis and hypothyroidism at our clinic were screened for inclusion in this study. All patients and control subjects provided their informed consent, and local ethics committee approval was obtained in accordance with the ethical standards of the Helsinki Declaration. The inclusion criteria were as follows: $\geq$ 18 years of age, newly diagnosed overt hypothyroidism or thyrotoxicosis without treatment and a body mass index (BMI) of $<30 \mathrm{~kg} / \mathrm{m}^{2}$. Patients with known diabetes or states of insulin resistance, such as impaired fasting glucose, impaired glucose tolerance or polycystic ovary syndrome, subjects using medications that have an effect on insulin and glucose metabolism (corticosteroids, insulin, oral antidiabetic agents) and individuals with organ failure or malignancy were excluded. Persons with central hypothyroidism were also excluded. The patients were matched with healthy controls according to age, sex and BMI. All female patients and controls were premenopausal.

\section{Anthropometric measurements and laboratory ex- aminations}

A complete physical examination, including measurements of height, weight, waist and hip circumference, blood pressure and pulse, was performed by the same physician in all subjects. The body mass index was calculated as the weight $(\mathrm{kg}) / \mathrm{height}^{2}\left(\mathrm{~m}^{2}\right)$. The fasting plasma glucose (FPG), fasting plasma insulin, lipid, TSH, free T3 (fT3), fT4, antithyroid peroxidase antibody and antithyroglobulin antibody levels were checked at the time of diagnosis and after the restoration of euthyroidism with appropriate therapy for at least eight weeks. The healthy control subjects were tested once. Blood samples were obtained from the antecubital vein after overnight fasting between 08:00 and 09:00 hours in the resting position. The serum concentrations of TSH, fT3 and fT4 were measured with an electrochemiluminescence immunoassay. The anti-thyroid peroxidase antibody and antithyroglobulin antibody titers were measured using a radioimmunoassay and chemiluminescent sequential immunometric assay, respectively. The immunoradiometric assay method was used to measure the fasting plasma insulin levels; the analytic sensitivity of the kit was $0.5 \mathrm{mIU} / \mathrm{mL}$. Plasma samples for adiponectin measurement were also obtained at the time of diagnosis and after the restoration of euthyroidism in the patients and once in the control subjects and subsequently stored at $-80^{\circ} \mathrm{C}$ until being assayed. The serum adiponectin levels were determined using a radioimmunassay with an adiponectin RIA kit produced by LINCO research $^{\circledR}$ (St.Charles, USA, 2006). The minimum level of detection on the assay for adiponectin was $1 \mathrm{ng} / \mathrm{mL}$.

The normal laboratory range was $60-100 \mathrm{mg} / \mathrm{dL}$ for the FPG level and 2.1-22 $\mathrm{mIU} / \mathrm{mL}$ for the fasting plasma insulin level. Overt thyrotoxicosis and hypothyroidism were diagnosed in compliance with the American Association of Clinical Endocrinologists medical guidelines for clinical practice for the evaluation and treatment of hyperthyroidism and hypothyroidism (25). The normal range was 0.27-4.2 $\mathrm{mIU} / \mathrm{mL}$ for the TSH level, 3.1-6.8 $\mathrm{pmol} / \mathrm{L}$ for the fT3 level and $12-22 \mathrm{pmol} / \mathrm{L}$ for the fT4 level.

\section{Metabolic assessment}

The insulin resistance index was calculated before and after treatment in the patients and once in the control group. The homeostatic model assessment (HOMA) index was used to evaluate the degree of insulin resistance and the beta cell function (26). The formulas for HOMA insulin resistance (HOMA-IR) and HOMA-beta cell function (HOMA-beta) were as follows:

HOMA-IR $=[$ Fasting plasma glucose $(\mathrm{mg} / \mathrm{dL}) \times$ Fasting plasma insulin $(\mathrm{mIU} / \mathrm{mL})] / 405$

HOMA-beta $=[20 \times$ fasting plasma insulin $(\mathrm{mIU} / \mathrm{mL})] /$ [Fasting plasma glucose (mg/dL) / 18-3.5] 
Table 1. Baseline Clinical and Laboratuary Characteristics of Patients and Controls.

\begin{tabular}{|c|c|c|c|c|}
\hline & $\begin{array}{c}\text { Hypothyroidism } \\
(\mathrm{n}=\mathbf{2 0})\end{array}$ & $\begin{array}{c}\text { Control } \\
(n=20)\end{array}$ & $\begin{array}{c}\text { Thyrotoxicosis } \\
(n=23)\end{array}$ & $\mathbf{p}$ \\
\hline Age & $42.0 \pm 11.6$ & $39.6 \pm 11.3$ & $37.9 \pm 10.5$ & 0.482 \\
\hline Sex (Female/Male) & $16 / 4$ & $14 / 6$ & $17 / 6$ & NA \\
\hline BMI $\left(\mathrm{kg} / \mathrm{m}^{2}\right)$ & $25.3 \pm 2.9$ & $25.9 \pm 2.5$ & $23.4 \pm 3.4^{\S}$ & 0.014 \\
\hline $\mathrm{TSH}(\mathrm{mIU} / \mathrm{mL})$ & $82.79 \pm 23.67^{\dagger \ddagger}$ & $1.83 \pm 0.90$ & $0.012 \pm 0.012$ & $<0.001$ \\
\hline fT3 (pmol/lL) & $3.83 \pm 6.90^{*}$ & $4.88 \pm 0.53$ & $17.92 \pm 11.35^{\S}$ & $<0.001$ \\
\hline fT4 (pmol/lL) & $5.77 \pm 2.85^{\ddagger}$ & $15.76 \pm 2.10$ & $49.25 \pm 27.54^{\S}$ & $<0.001$ \\
\hline $\mathrm{FPG}(\mathrm{mg} / \mathrm{dL})$ & $82.25 \pm 10.50^{\dagger \star}$ & $91.8 \pm 10.01$ & $98.39 \pm 11.96$ & $<0.001$ \\
\hline $\begin{array}{l}\text { Fasting plasma insulin } \\
(\mathrm{mIU} / \mathrm{mL})\end{array}$ & 22 & $8.88=$ & & 0.329 \\
\hline $\mathrm{HON}$ & 1.8 & 2.04 & & 0.089 \\
\hline HOMA-beta ${ }^{*}$ & $149.25 / 92.30^{\ddagger}$ & $113.84 / 89.16$ & $100.46 / 60.0$ & 0.038 \\
\hline Total cholestero & $239.4 \pm 48.66^{\dagger \star}$ & $171.9 \pm 45.39$ & $153.70 \pm 32.68$ & $<0.001$ \\
\hline Triglyceride (mg/dL) & $139.75 \pm 60.75^{\dagger}$ & $95.4 \pm 39.45$ & $105.74 \pm 53.83$ & 0.024 \\
\hline $\mathrm{LDL}(\mathrm{mg} / \mathrm{dL})$ & $165.45 \pm 47.57^{\dagger *}$ & $111.55 \pm 40.1$ & $78.91 \pm 30.96^{\S}$ & $<0.001$ \\
\hline HDL (mg/dL) & $57.25 \pm 13.60^{\dagger}$ & $48.6 \pm 8.92$ & $54.28 \pm 11.12$ & 0.057 \\
\hline Adiponectin $(\mathrm{mcg} / \mathrm{mL})$ & $14.55 \pm 8.40$ & $11.68 \pm 6.0$ & $13.79 \pm 9.13$ & 0.503 \\
\hline \multicolumn{5}{|c|}{$\begin{array}{l}\text { BMI: Body mass index, TSH: Thyrotropin, fT3: Free T3, fT4: Free T4, FPG: Fasting plasma } \\
\text { glucose, HOMA-IR: Homeostatic model assessment-insulin resistance, HOMA-beta: } \\
\text { Homeostatic model assessment-beta cell function, LDL:Low density lipopotein, HDL: High } \\
\text { density lipoprotein, NA: Not applicable } \\
* \text { data median and interquartile range } \\
{ }^{p}<0.05 \text { hypothyroid patients vs. controls, } \\
{ }^{\ddagger} \mathrm{p}<0.05 \text { hypothyroid patients vs. thyrotoxic patients, } \\
\mathrm{p}<0.05 \text { thyrotoxic patients vs. controls }\end{array}$} \\
\hline
\end{tabular}

\section{Management of the patients}

When needed, thyroid ultrasonography, scintigraphy and radioactive iodine uptake assessments were performed to identify the underlying cause of disease and plan the treatment strategy. In both groups, in cases of nodular goiters, a thyroid fine-needle aspiration biopsy of the nodule or nodules was performed according to the "American Association of Clinical Endocrinology and Associazione Medici Endocrinologi" guidelines published in 2006 (27). Thyrotoxic patients were administered propylthiouracil (with the dose tapered down from $300 \mathrm{mg} /$ day) and/or propranolol (40-120 $\mathrm{mg} /$ day for two weeks) according to the underlying pathology in order to maintain the thyroid function within the normal limits. Hypothyroid patients were administered Lthyroxine, and the initial dose was chosen based on the patient's age and cardiovascular risk. Thyroid function parameters were reevaluated in the thyrotoxic and hypothyroid patients every 3-4 weeks.

\section{Statistical analysis}

All data were analyzed using the SPSS software program (Statistical Package for the Social Sciences for Windows, Chicago, USA), version 9.05. Comparisons of means between two groups were made using Student's $t$-test. An analysis of variance (ANOVA) was used to compare means between more than two groups. For paired data, statistical analyses of the values obtained before and after therapy were carried out using the paired Student's $t$-test. The Chisquare test was used to investigate differences between the groups in terms of categorical variables. Correlations between the variables were assessed using Pearson and Spear- man correlation analyses for parametric and nonparametric variables, respectively. A $\mathrm{p}$ value of less than 0.05 was considered to indicate statistical significance.

\section{Results}

Twenty-four patients with overt hypothyroidism and 30 patients with overt thyrotoxicosis were included in this study. Data for 20 hypothyoid patients, 23 thyrotoxic patients and 20 control subjects were analyzed. Four hypothyroid and seven thyrotoxic patients were excluded because they were not euthyroid at the end of the study. The mean age and sex distributions were identical in all groups (Table 1). The thyrotoxic patients had lower BMI values than the hypothyroid and control groups; however, only the difference between the thyrotoxic and control groups was significant $(\mathrm{p}=0.016)$. The underlying causes of hypothyroidism included Hashimoto's thyroiditis, postoperative hypothyroidism and postradioactive iodine hypothyroidism in 15, three and two patients, respectively. Thyrotoxicosis was secondary to Graves' disease, subacute thyroiditis, autonomously functioning nodules and Hashitoxicosis in 13, five, three and two patients, respectively. With appropriate management, euthyroidism was achieved in $4.7 \pm 2.49$ months in the hypothyroid patients and $7.17 \pm 4.0$ months in the thyrotoxic patients. The baseline biochemical and hormonal results of the patients and control subjects are shown in Table 1. There were statistically significant differences between the groups in terms of the FPG levels $(\mathrm{p}<0.001)$. In addition, the thyrotoxic patients had higher fasting plasma insulin levels than both the hypothyroid and control individuals, although the differences did not reach statistical significance $(\mathrm{p}=0.329)$. The HOMA- 
Table 2. Characteristic of Thyrotoxic and Hypothyroid Patients before and after Restoration of Euthyroidism.

\begin{tabular}{|c|c|c|c|c|c|c|}
\hline & \multicolumn{3}{|c|}{ Hypothyroidism $(n=20)$} & \multicolumn{3}{|c|}{ Thyrotoxicosis $(n=23)$} \\
\hline & Basal & Post-treatment & $\mathrm{p}$ & Basal & Post-treatment & $\mathrm{p}$ \\
\hline BMI $\left(\mathrm{kg} / \mathrm{m}^{2}\right)$ & $25.3 \pm 2.9$ & $24.7 \pm 2.8$ & 0.040 & $23.4 \pm 3.4$ & $24.1 \pm 4.1$ & 0.075 \\
\hline TSH (mIU/mL) & $82.79 \pm 23.67$ & $2.20 \pm 1.49$ & $<0.001$ & $0.012 \pm 0.012$ & $1.94 \pm 1.21$ & $<0.001$ \\
\hline fT3 $(\mathrm{pmol} / \mathrm{L})$ & $3.83 \pm 6.90$ & $4.73 \pm 0.82$ & 0.555 & $17.92 \pm 11.35$ & $4.56 \pm 0.71$ & $<0.001$ \\
\hline $\mathrm{fT} 4(\mathrm{pmol} / \mathrm{L})$ & $5.77 \pm 2.85$ & $17.53 \pm 2.59$ & $<0.001$ & $49.25 \pm 27.54$ & $14.57 \pm 1.73$ & $<0.001$ \\
\hline FPG (mg/dL) & $82.25 \pm 10.50$ & $91.55 \pm 9.99$ & 0.002 & $98.39 \pm 11.97$ & $90.78 \pm 12.28$ & 0.001 \\
\hline $\begin{array}{l}\text { Fasting plasma } \\
\text { insulin }(\mathrm{mIU} / \mathrm{mL})\end{array}$ & $8.64 \pm 4.22$ & $9.47 \pm 3.92$ & 0.433 & $10.49 \pm 5.08$ & $8.59 \pm 4.58$ & 0.161 \\
\hline HOMA-IR & $1.81 \pm 1.11$ & $2.13 \pm 0.91$ & 0.204 & $2.57 \pm 1.31$ & $1.98 \pm 1.22$ & 0.075 \\
\hline HOMA-beta* & $214.35 \pm 204.77$ & $145.45 \pm 110.60$ & 0.182 & $117.34 \pm 66.60$ & $128.72 \pm 71.95$ & 0.533 \\
\hline $\begin{array}{l}\text { Total cholesterol } \\
(\mathrm{mg} / \mathrm{dL})\end{array}$ & $239.40 \pm 48.66$ & $205.70 \pm 48.52$ & 0.014 & $153.70 \pm 32.68$ & $200.78 \pm 36.94$ & 0.001 \\
\hline $\begin{array}{l}\text { Triglyceride } \\
(\mathrm{mg} / \mathrm{dL})\end{array}$ & $139.75 \pm 60.75$ & $127.05 \pm 60.92$ & 0.260 & $105.74 \pm 53.83$ & $108.70 \pm 37.21$ & 0.769 \\
\hline LDL (mg/dL) & $165.45 \pm 47.57$ & $136.65 \pm 43.57$ & 0.027 & $78.91 \pm 30.96$ & $126.52 \pm 34.09$ & 0.001 \\
\hline HDL (mg/dL) & $57.25 \pm 13.60$ & $51.35 \pm 6.13$ & 0.030 & $54.28 \pm 11.2$ & $59.97 \pm 13.36$ & 0.025 \\
\hline $\begin{array}{l}\text { Adiponectin } \\
(\mathrm{mcg} / \mathrm{mL})\end{array}$ & $14.55 \pm 8.40$ & $11.44 \pm 6.02$ & 0.047 & $13.79 \pm 9.13$ & $14.31 \pm 5.33$ & 0.070 \\
\hline $\begin{array}{l}\text { BMI: Body mass } \\
\text { Homeostatic mod } \\
\text { LDL:Low density } \\
\text { * data median and }\end{array}$ & $\begin{array}{l}\text { x, TSH: Thyrotr } \\
\text { sessment-insulin } \\
\text { potein, HDL: Hi }\end{array}$ & $\begin{array}{l}\text { n, fT3: Free T3 } \\
\text { sistance, HOM }\end{array}$ & $\begin{array}{l}\text { Fre } \\
\text { a: } H\end{array}$ & $\begin{array}{l}\text { FPG: Fastin } \\
\text { static model } \\
\text { pplicable }\end{array}$ & $\begin{array}{l}\text { ma glucose, } \\
\text { ment-beta ce }\end{array}$ & $\begin{array}{l}\text { IA-IR: } \\
\text { action, }\end{array}$ \\
\hline
\end{tabular}

IR values were similar in all groups $(\mathrm{p}=0.089)$. The hypothyroid patients had significantly higher HOMA-beta values than the thyrotoxic patients $(\mathrm{p}=0.015)$. The total cholesterol, triglyceride, low-density lipoprotein (LDL) and high-density lipoprotein (HDL) levels were significantly higher in the hypothyroid patients than in the control subjects. In the thyrotoxic patients, among the lipid parameters, only the LDL levels were significantly lower than that observed in the euthyroid subjects.

Although the BMI values significantly decreased in the hypothyroid patients after the restoration of euthyroidism $(p=0.04)$, no significant changes were observed in the thyrotoxic patients $(\mathrm{p}=0.075)$. Table 2 shows the clinical and biochemical characteristics of the patients before and after treatment for thyroid dysfunction. Treatment for hypothyroidism resulted in a significant increase in the FPG levels $(\mathrm{p}=0.002)$, while treatment for thyrotoxicosis resulted in a significant decrease in this parameter $(\mathrm{p}=0.001)$. Following the restoration of euthyroidism, the fasting plasma insulin and HOMA-IR values increased in the hypothyroid patients and decreased in the thyrotoxic patients; however, the differences were not statistically significant. In addition, the HOMA-beta levels did not change significantly after treatment in the two groups. Meanwhile, the total cholesterol, LDL and HDL levels decreased after treatment in the hypothyroid patients $(\mathrm{p}=0.014, \mathrm{p}=0.027$ and $\mathrm{p}=0.030$, respectively) and increased after treatment in the thyrotoxic patients $(\mathrm{p}<0.001, \mathrm{p}<0.001$ and $\mathrm{p}=0.025$, respectively). The attainment of euthyroidism did not alter the triglyceride levels in either group.

The basal plasma adiponectin levels were $14.55 \pm 8.4 \mathrm{mcg} /$ $\mathrm{mL}, 13.79 \pm 9.13 \mathrm{mcg} / \mathrm{mL}$ and $11.68 \pm 6.0 \mathrm{mcg} / \mathrm{mL}$ in the hypothyroid and thyrotoxic patients and healthy controls, respectively $(\mathrm{p}=0.503)$ (Table 1$)$. The adiponectin levels in the hypothyroid patients significantly decreased following treatment with L-thyroxine therapy $(\mathrm{p}=0.047)$, and the significance of this trend remained after correcting the analysis for BMI. Meanwhile, treatment for thyrotoxicosis resulted in an insignificant increase in the adiponectin levels $(\mathrm{p}=0.770)$. Analyzing all groups together under euthyroid conditions, the adiponectin levels were significantly higher in women than in men $(13.70 \pm 6.03 \mathrm{mcg} / \mathrm{mL}$ vs. $9.22 \pm 3.61 \mathrm{mcg} / \mathrm{mL}$, $\mathrm{p}=0.007)$ and in normal-weight patients versus overweight patients $(14.11 \pm 5.88 \mathrm{mcg} / \mathrm{mL}$ vs. $10.96 \pm 5.42 \mathrm{mcg} / \mathrm{mL}, \mathrm{p}=$ $0.031)$.

When the data for the patients with Graves' disease were analyzed separately, we observed the findings for the overall thyrotoxic patients, in both the basal state and after treatment, to be nearly completely representative of Graves' disease patients, with some minor differences. In these patients, the FPG levels were significantly higher and the total cholesterol and LDL levels were significantly lower than that observed in the hypothyroid patients. Different from that seen in the overall thyrotoxic group, the HOMA-beta values were similar between the patients with Graves' disease and those in the hypothyroid group and the LDL levels were similar between the patients with Graves' disease and the control subjects. Treatment for hyperthyroidism in these patients also led to a significant decrease in the FPG levels and increase in the total, LDL and HDL cholesterol levels, such as that noted in the thyrotoxic patients. However, different from that observed in the overall thyrotoxic group, the attainment of euthyroidism in the patients with Graves' disease resulted in a marked decrease in the HOMA-IR values, particularly due to the higher basal insulin levels and lower post-treatment insulin levels compared to that seen in the thyrotoxic patients. The basal and post-treatment adiponectin levels in the patients with Graves' disease were 
Table 3. Correlation Analysis between Basal TSH, fT3, fT4 and Clinical and Laboratuary Characteristics Including All Subjects.

\begin{tabular}{|c|c|c|c|c|c|c|}
\hline & \multicolumn{2}{|c|}{ Basal TSH } & \multicolumn{2}{|c|}{ Basal fT3 } & \multicolumn{2}{|c|}{ Basal fT4 } \\
\hline & rs & $\mathrm{p}$ & rs & $\mathrm{p}$ & rs & $\mathrm{p}$ \\
\hline BMI $\left(\mathrm{kg} / \mathrm{m}^{2}\right)$ & 0.290 & 0.021 & -0.309 & 0.014 & -0.295 & 0.019 \\
\hline $\mathrm{FPG}(\mathrm{mg} / \mathrm{dL})$ & -0.542 & $<0.001$ & 0.479 & $<0.001$ & 0.556 & $<0.001$ \\
\hline Fasting plasma insulin (mIU/mL) & -0.171 & 0.181 & 0.215 & 0.090 & 0.171 & 0.180 \\
\hline HOMA-IR & -0.298 & 0.018 & 0.311 & 0.013 & 0.303 & 0.016 \\
\hline HOMA-beta & 0.332 & 0.008 & -0.259 & 0.041 & -0.324 & 0.010 \\
\hline Total cholesterol (mg/dL) & 0.631 & $<0.001$ & -0.599 & $<0.001$ & -0.627 & $<0.001$ \\
\hline Triglyceride (mg/dL) & 0.321 & 0.010 & -0.293 & 0.020 & 0.266 & $\mathbf{0 . 0 3 5}$ \\
\hline $\mathrm{LDL}(\mathrm{mg} / \mathrm{dL})$ & 0.675 & $<0.001$ & -0.663 & $<0.001$ & -0.680 & $<0.001$ \\
\hline $\mathrm{HDL}(\mathrm{mg} / \mathrm{dL})$ & 0.064 & 0.618 & -0.039 & 0.759 & -0.630 & 0.622 \\
\hline Adiponectin $(\mathrm{mcg} / \mathrm{mL})$ & 0.055 & 0.667 & -0.044 & 0.733 & -0.260 & 0.838 \\
\hline $\begin{array}{l}\text { TSH: Thyroid stimulating hormo } \\
\text { Fasting plasma glucose, HOMA-I } \\
\text { beta: Homeostatic model assessn } \\
\text { High density lipoprotein, rs: Spea }\end{array}$ & $\begin{array}{l}\mathrm{fT} 3: \\
\text { Hom }\end{array}$ & $\begin{array}{l}\text { T3, } \\
\text { atic m }\end{array}$ & ree $\mathrm{T}$ & BMI: & $\begin{array}{l}\text { mass } \\
\text { esistan }\end{array}$ & $\begin{array}{l}\text { FPG: } \\
\text { IOMA- } \\
\text { HDL: }\end{array}$ \\
\hline
\end{tabular}

$15.75 \pm 11.03 \mathrm{mcg} / \mathrm{mL}$ and $16.85 \pm 4.36 \mathrm{mcg} / \mathrm{mL}$, respectively $(\mathrm{p}=0.697)$.

In the correlation analysis including all subjects, the basal TSH level was found to be negatively correlated with the basal FPG and HOMA-IR values and positively correlated with the basal HOMA-beta, total cholesterol, triglyceride and LDL values (Table 3). The reverse associations were also true for the basal fT3 and fT4 levels, and there were no correlations between the basal adiponectin levels and the basal BMI, TSH, thyroid hormone, FPG, insulin, HOMA-IR, HOMA-beta and lipid values in the patients with hypothyroidism and thyrotoxicosis.

\section{Discussion}

The effects of thyroid hormones on glucose tolerance and insulin secretion have remained controversial for years. In different studies, mostly including small sample sizes, hyperthyroidism has been reported to be associated with glucose intolerance $(11,28)$. However Gonzalo et al. showed no changes in glucose metabolism in the hyperthyroid patients with a normal weight (10). There are also conflicting results regarding the effects of insulin resistance in patients with hypothyroidism. In hypothyroid animal models, a decreased rate of insulin infusion using an euglycemic hyperinsulinemic clamp has been demonstrated, despite normal levels of basal glucose and insulin (29). This observation is explained by the lower levels of insulin resistance and glucose utilization in muscle and adipose tissue in hypothyroid animals. Owecki et al. reported significantly lower FPG levels in hypothyroid patients versus euthyroid subjects, although the plasma insulin, HOMA-IR and HOMA-beta values were similar (30). Our findings are consistent with the results of that study. In particular, we demonstrated that the FPG and insulin resistance index values in patients with thyrotoxicosis are identical to those observed in control subjects. However, the FPG levels were significantly higher and the HOMA-beta values were significantly lower in the thyrotoxic patients than in the hypothyroid patients. To our knowledge, this is the first study to evaluate the HOMAbeta values in thyrotoxic patients. When all patients were pooled, the basal TSH levels were found to be negatively correlated with the FPG and HOMA-IR values and positively correlated with the HOMA-beta values. In other words, insulin resistance developed as the TSH levels decreased. In addition, the levels of thyroid hormones were positively correlated with the FPG and HOMA-IR values and negatively correlated with the HOMA-beta values. These findings suggest that thyrotoxicosis is associated with higher FPG levels and worsening of the beta cell function. Beta cell apoptosis via an unknown mechanism has been demonstrated in the pancreas in L-thyroxine administered rats (31). Additionally, it is thought that the phenomena rapid gastric emptying and glucose absorption in thyrotoxic patients result in postprandial hyperglycemia and an increased insulin response, thus causing insulin resistance $(32,33)$. However, Fukuchi et al. detected higher glucose levels and a lower insulin response to oral glucose loading in rats given intraperitoneal L-thyroxine and suggested that the abnormal glucose tolerance observed in cases of hyperthyroidism is related to a decreased pancreatic cell response rather than peripheral resistance (34). The decreased HOMA-beta values and lack of insulin resistance observed in our thyrotoxic patients provide support for this hypothesis.

In a recent study of 30 hyperthyroid subjects, the plasma glucose, insulin and c-peptide levels significantly decreased after one month of antithyroid treatment (35). Another study detected significantly higher insulin sensitivity using the euglycemic insulin clamp technique in the euthyroid state versus the hyperthyroid state (36). These findings are similar to those of other studies showing affirmative changes in glucose and insulin metabolism after treatment for hyperthyroidism $(28,37)$. In the current study, compared to that observed in the thyrotoxic state, the FPG levels significantly decreased after the attainment of euthyroidism. Limited studies examining glucose metabolism in hypothyroid patients have reported that both insulin sensitivity and secre- 
tion normalize with treatment for hypothyroidism (13). Our findings indicate that treatment for hypothyroidism results in a significant increase in the FPG level, whereas the insulin resistance index and beta cell function do not change.

Since adiponectin is a relatively new adipokine, reports investigating the adiponectin levels in patients with thyroid dysfunction are limited. The first such study conducted by Iglesias et al. in 2003 found similar adiponectin levels in 20 hyperthyroid patients, 20 hypothyroid patients and 20 euthyroid subjects (24). In different studies, the adiponectin levels have also been reported to be significantly higher in hyperthyroid patients than in hypothyroid patients or control subjects $(19,21)$. While experimental hyperthyroidism induces increases in the adiponectin levels, experimental hypothyroidism does not result in any significant changes (23). However, in a recent study, although the hypothyroid group had the highest adiponectin levels, no significant differences were reported among the hypothyroid, hyperthyroid and euthyroid subjects (22). We also found similar results in the current study. Since the adiponectin levels are decreased in patients with insulin resistance, they are also expected to be decreased in patients with hyperthyroidism, a condition that has been shown to be related to insulin resistance. However, neither this study nor most previously published studies have demonstrated such significantly decreased adiponectin levels in individuals with hyperthyroidism. Various explanations for this discrepancy have been suggested. One possible explanation involves the induction of TSH receptors on adipose cells via the effects of TSH-stimulating antibodies, thus resulting in increased adiponectin production (38). Direct stimulation of adiponectin by thyroid hormones through the peroxisome proliferator-activated receptor (PPAR) signaling pathway is another hypothesis $(39,40)$. Other proposed mechanisms include an increase in the number of adrenergic receptors and enhanced lipolysis in addition to an increased number of small adipocytes responsible for adiponectin production $(41,42)$. None of these mechanisms have yet been proven in molecular or experimental studies.

To the best of our knowledge, there is only a single study evaluating the adiponectin levels before and after treatment in both hypothyroid and thyrotoxic patients. In that study, Iglesias et al. demonstrated that, after treatment, the adiponectin levels increased in the patients with hyperthyroidism and decreased in those with hypothyroidism, although these changes were not statistically significant (24). Another study reported that patients with Basedow disease have significantly higher serum adiponectin levels in the hyperthyroid state than in the euthyroid state; however, that study was not designed to investigate changes before and after treatment and instead included two different groups of patients (18). Recently, in a study by Hsieh et al., the serum adiponectin concentrations were reported to have significantly decreased after treatment in patients with hyperthyroidism (43). In the present study, the adiponectin levels decreased significantly in the patients hypothyroidism following the restoration of euthyroidism. Nevertheless, the in- crease in the adiponectin levels observed with treatment in the patients with thyrotoxicosis did not reach statistical significance.

Few studies have investigated the association between the adiponectin levels and abnormalities of glucose metabolism in patients with thyroid dysfunction, with no relationships found in the majority of reports $(19,20,22)$. Although Iglesias et al. documented insulin resistance in individuals with hyperthyroidism, due to the similar adiponectin levels observed in the hypothyroid, hyperthyroid and euthyroid states, they concluded that adiponectin does not play a role in the pathogenesis of insulin resistance in cases of thyroid dysfunction (24). Similar results were obtained by $\mathrm{Chu}$ et al, who concluded that insulin resistance associated with hyperthyroidism is not mediated by a reduction in the adiponectin level (44). Meanwhile, one study that evaluated patients with Graves' disease when both thyrotoxic and hypothyroid also found no associations between the HOMA-IR and adiponectin values (19). Moreover, Altinova et al. observed significantly higher HOMA-IR values in hyperthyroid patients than in hypothyroid and euthyroid subjects; however, since the adiponectin levels were similar between the group, the authors were unable to clarify the role of adiponectin in the development of insulin resistance in the setting of hyperthyroidism (20). In another study, the serum concentrations of adiponectin and leptin were found to be similar in hyperthyroid, hypothyroid and euthyroid individuals (22). The authors subsequently concluded that metabolic changes associated with thyroid dysfunction are not related to variations in the serum levels of these adipokines. Contrary to these clinical findings, the adiponectin gene expression was recently shown to be increased in hyperthyroid rats, and a significant positive correlation between the adiponectin and glucose levels has been reported (40). These observations suggest the possible role of changes in the adiponectin gene expression in glucose metabolism in patients with thyroid dysfunction. Yu et al. observed significantly lower FPG, insulin and HOMA-IR values and higher adiponectin levels in hypothyroid patients than in euthyroid subjects (21). In the thyrotoxic patients, the FPG, insulin, HOMA-IR and adiponectin levels were each higher than those observed in the euthyroid control group. As adiponectin is an adipokine known to be suppressed in states of insulin resistance, it is controversial to find higher adiponectin levels in patients with hyperthyroidism, a condition associated with insulin resistance. If true, these findings indicate that the negative association between adiponectin and insulin resistance is reversed in cases of hyperthyroidism. Suggested mechanisms for this unexpected finding are discussed above. In addition, the detection of increased or inappropriately normal adiponectin levels in patients with hyperthyroidism may represent the effects of a compensatory mechanism against insulin resistance in this state.

We observed no significant correlations between the adiponectin levels and FPG, fasting plasma insulin, HOMA-IR and HOMA-beta values in the patients with hypothyroidism 
and thyrotoxicosis. This was also the case when we analyzed all groups together after the restoration of euthyroidism. This result is in contrast with the findings of studies showing insulin resistance in individuals with adiponectin deficiency. However, it should be noted that, contrary to the findings of decreased adiponectin levels in patients with insulin resistance, a few recent studies have shown no such correlations. For example, no significant associations between the adiponectin and HOMA-IR values were found among 166 healthy Japanese men (45). The adiponectin and HOMA-beta values have been examined in far fewer studies. Hung et al. investigated the HOMA-IR, HOMA-beta and adiponectin levels in 580 children and found that only the adiponectin and HOMA-IR levels in girls were significantly correlated (46). In recent years, high-molecularweight multimers of adiponectin, rather than adiponectin itself, have been suggested to be better markers of insulin resistance (47). There is a possibility that we may have obtained different results in the present study if we had measured the high-molecular-weight adiponectin levels. In addition, the adiponectin levels have been found to be different in various ethnic groups. For example, this parameter was shown to be related to insulin resistance in African Americans, but not Caucasions, in one study (48). Such ethnic variation may have confounded our data.

In most publications, hypothyroidism has been found to be related to high total cholesterol, LDL cholesterol and triglyceride levels $(49,50)$. The effect of hyperthyroidism on lipid metabolism is opposite to that of hypothyroidism. In the thyrotoxic state, fatty acids are used as an energy source and the production of lipoprotein lipase is stimulated (51). The significantly higher lipid levels noted in the hypothyroid patients versus the healthy subjects in this study are consistent with the literature. Only the LDL cholesterol levels were significantly lower in the thyrotoxic group than in the control group. Furthermore, treatment for hypothyroidism and thyrotoxicosis led to significant decreases and increases in the total cholesterol and LDL levels, respectively. Although previous authors have demonstrated atherogenic lipid profiles in patients with decreased adiponectin levels $(2,7)$, some have reported increased triglyceride levels with no changes in the total cholesterol levels $(4,5)$ and others have found no relationships between the adiponectin and lipid levels (3). Altinova et al. showed that the adiponectin level is positively correlated with the HDL level and negatively correlated with the triglyceride level in both patients with hypothyroidism and hyperthyroidism (20); however, they found no correlations with the total cholesterol or LDL levels. In another study, Yu et al. reported no relationships between the adiponectin and lipid levels in subjects with hypothyroidism and hyperthyroidism (21). Our results are similar to those of the latter study, suggesting that adiponectin plays no role in the altered lipid metabolism observed in patients with thyroid dysfunction.

\section{Conclusion}

In conclusion, we showed that hypothyroid patients have lower FPG levels within the normal ranges and that this glycemic aberration appears to resolve following treatment for hypothyrodism. In the present study, the basal FPG levels were similar between the patients with thyrotoxicosis and the euthyroid subjects, although the attainment of euthyroidism significantly decreased the FPG levels. Therefore, glucose metabolism should be evaluated in patients with thyroid dysfunction following normalization of thyroid hormones. Furthermore, the basal serum adiponectin levels were similar in the hypothyroid, thyrotoxic and euthyroid groups in this study, and the adiponectin levels did not change in the patients with thyrotoxicosis after the attainment of euthyroidism. Although this study did not include sufficent data to show a direct association between the adiponectin level and thyroid dysfunction-related abnormalities in glucose and lipid metabolism, our finding that treatment for hypothyroidism results in a significant increase in the FPG level and significant decrease in the adiponectin level indicates the need for further studies with larger sample sizes to clarify the possible relationship between adiponectin and thyroid dysfunction.

This research was previously presented in oral communication form at the 2010 European Congress of Endocrinology in Prague, Czech Republic.

The authors state that they have no Conflict of Interest (COI).

\section{References}

1. Kadowaki T, Yamauchi T, Kubota N, Hara K, Ueki K, Tobe K. Adiponectin and adiponectin receptors in insulin resistance, diabetes, and the metabolic syndrome. J Clin Invest 116: 1784-1792, 2006.

2. Snijder MB, Heine RJ, Seidell JC, et al. Associations of adiponectin levels with incident impaired glucose metabolism and type 2 diabetes in older men and women. Diabetes Care 29: 24982503, 2006.

3. Altinova AE, Toruner F, Bukan N, Yasar DG, Akturk M, Cakir N. Decreased plasma adiponectin is associated with insulin resistance and HDL cholesterol in overweight subjects. Endocr J 54: 221226, 2007.

4. Daimon M, Oizumi T, Saitoh H, et al. Decreased serum levels of adiponectin are a risk factor for the progression to type 2 diabetes in the Japanese population: the Funagata study. Diabetes Care 26: 2015-2020, 2003.

5. Tschritter O, Fritsche A, Thamer C, et al. Plasma adiponectin concentrations predict insulin sensitivity of both glucose and lipid metabolism. Diabetes 52: 239-243, 2003.

6. Spranger J, Kroke A, Möhlig M, et al. Adiponectin and protection against type 2 diabetes mellitus. Lancet 361: 226-228, 2003.

7. Matsubara M, Maruoka S, Katayose S. Decreased plasma adiponectin concentrations in women with dyslipidemia. J Clin Endocrinol Metab 87: 2764-2769, 2002.

8. Adamczak M, Wiecek A, Funahashi T, Chudek J, Kokot F, Matsuzawa Y. Decreased plasma adiponectin concentration in pa- 
tients with essential hypertension. Am J Hypertens 16: 72-75, 2003.

9. Dimitriadis G, Mitrou P, Lambadiari V, et al. Insulin-stimulated rates of glucose uptake in muscle in hyperthyroidism: the importance of blood flow. J Clin Endocrinol Metab 93: 2413-2415, 2008.

10. Gonzalo M, Grant C, Moreno I, et al. Glucose tolerance, insulin secretion, insulin sensitivity and glucose effectiveness in normal and overweight hyperthyroid women. Clin Endocrinol 45: 689697, 1996.

11. Ohguni S, Notsu K, Kato Y. Correlation of plasma free thyroxine levels with insulin sensitivity and metabolic clearance rate of insulin in patients with hyperthyroid Graves' disease. Intern Med 34: 339-413, 1995.

12. Al Sayed A, Al Ali N, Bo Abbas Y, Alfadhli E. Subclinical hypothyroidism is associated with early insulin resistance in Kuwaiti women. Endocr J 53: 653-657, 2006.

13. Stanická $S$, Vondra K, Pelikánová T, Vleck $P$, Hill M, Zamravil V. Insulin sensitivity and counter-regulatory hormones in hypothyroidism and during thyroid hormone replacement therapy. Clin Chem Lab Med 43: 715-720, 2005.

14. Bell A, Gagnon A, Grunder L, Parikh SJ, Smith TJ, Sorisky A. Functional TSH receptor in human abdominal preadipocytes and orbital fibroblasts. Am J Physiol Cell Physiol 279: C335-C340, 2000.

15. Nannipieri M, Cecchetti F, Anselmino M, et al. Expression of thyrotropin and thyroid hormone receptors in adipose tissue of patients with morbid obesity and/or type 2 diabetes: effects of weight loss. Int J Obes 33: 1001-1006, 2009.

16. Fasshauer M, Klein J, Neumann S, Eszlinger M, Paschke R. Hormonal regulation of adiponectin gene expression in 3T3-L1 adipocytes. Biochem Biophys Res Commun 290: 1084-1089, 2002.

17. Cabanelas A, Cordeiro A, Santos Almeida NA, et al. Effect of Triiodothyronine on Adiponectin Expression and Leptin Release by White Adipose Tissue of Normal Rats. Horm Metab Res 42: 254260, 2010.

18. Saito T, Kawano T, Saito T, et al. Elevation of serum adiponectin levels in Basedow disease. Metabolism 54: 1461-1466, 2005.

19. Yaturu S, Prado S, Grimes SR. Changes in adipocyte hormones leptin, resistin, and adiponectin in thyroid dysfunction. J Cell Biochem 93: 491-496, 2004

20. Altinova $\mathrm{AE}$, Törüner $\mathrm{FB}$, Aktürk $\mathrm{M}$, et al. Adiponectin levels and cardiovascular risk factors in hypothyroidism and hyperthyroidism. Clin Endocrinol 65: 530-535, 2006.

21. Yu H, Yang $Y$, Zhang $M$, et al. Thyroid status influence on adiponectin, acylation stimulating protein (ASP) and complement C3 in hyperthyroid and hypothyroid subjects. Nutr Metab 3: 13, 2006.

22. Santini F, Marsili A, Mammoli C, et al. Serum concentrations of adiponectin and leptin in patients with thyroid dysfunctions. J Endocrinol Invest 27: RC5-RC7, 2004.

23. Aragão CN, Souza LL, Cabanelas A, Oliveira KJ, Pazos-Moura CC. Effect of experimental hypo- and hyperthyroidism on serum adiponectin. Metabolism 56: 6-11, 2007.

24. Iglesias P, Alvarez Fidalgo P, Codoceo R, Díez JJ. Serum concentrations of adipocytokines in patients with hyperthyroidism and hypothyroidism before and after control of thyroid function. Clin Endocrinol 59: 621-629, 2003.

25. Baskin HJ, Cobin RH, Duick DS, et al; American Association of Clinical Endocrinologists. American Association of Clinical Endocrinologists medical guidelines for clinical practice for the evaluation and treatment of hyperthyroidism and hypothyroidism. Endocr Pract 8: 457-469, 2002.

26. Matthews DR, Hosker JP, Rudenski AS, Naylor BA, Treacher DF, Turner RC. Homeostasis model assessment: insulin resistance and beta-cell function from fasting plasma glucose and insulin concentrations in man. Diabetologia 28: 412-419, 1985.
27. Gharib H, Papini E, Valcavi R, et al; AACE/AME Task Force on Thyroid Nodules. American Association of Clinical Endocrinologists and Associazione Medici Endocrinologi medical guidelines for clinical practice for the diagnosis and management of thyroid nodules. Endocr Pract 12: 63-102, 2006.

28. Jap TS, Ho LT, Won JG. Insulin secretion and sensitivity in hyperthyroidism. Horm Metab Res 21: 261-266, 1989.

29. Cettour-Rose P, Theander-Carrillo C, Asensio C, et al. Hypothyroidism in rats decreases peripheral glucose utilisation, a defect partially corrected by central leptin infusion. Diabetologia 48: 624-633, 2005.

30. Owecki M, Nikisch E, Sowiński J. Hypothyroidism has no impact on insulin sensitivity assessed with HOMA-IR in totally thyroidectomized patients. Acta Clin Belg 61: 69-73, 2006.

31. Jörns A, Tiedge M, Lenzen S. Thyroxine induces pancreatic beta cell apoptosis in rats. Diabetologia 45: 851-855, 2002.

32. Ikeda $T$, Fujiyama $K$, Hoshino $T$, Takeuchi $T$, Tominaga $M$, Mashiba H. Glucose tolerance and gastric emptying in thyrotoxic rats. Metabolism 38: 874-877, 1989.

33. Debiec H, Cross HS, Peterlik M. D-glucose uptake is increased in jejunal brush-border membrane vesicles from hyperthyroid chicks. Acta Endocrinol (Copenh) 120: 435-441, 1989.

34. Fukuchi M, Shimabukuro M, Shimajiri Y, et al. Evidence for a deficient pancreatic beta-cell response in a rat model of hyperthyroidism. Life Sci 71: 1059-1070, 2002.

35. Al-Shoumer KA, Vasanthy BA, Al-Zaid MM. Effects of treatment of hyperthyroidism on glucose homeostasis, insulin secretion, and markers of bone turnover. Endocr Pract 12: 121-130, 2006.

36. Tene $\mathrm{C}$, Zárate $\mathrm{A}$, Basurto $\mathrm{L}$, et al. Correction of insulin resistance in methimazole-treated patients with Graves disease. Rev Invest Clin 53: 531-535, 2001.

37. Yamada T, Shirota T, Aizawa T, Takasu N. Blood glucose, serum thyroid hormones, insulin, C-peptide and C-peptide/insulin ratio in hyperthyroid patients. Horm Metab Res 23: 504-505, 1991.

38. Kumar S, Nadeem S, Stan MN, Coenen M, Bahn RS. A stimulatory TSH receptor antibody enhances adipogenesis via phosphoinositide 3-kinase activation in orbital preadipocytes from patients with Graves' ophthalmopathy. J Mol Endocrinol 46: 155-163, 2011.

39. Seifi S, Nazifi S, Tabandeh MR, Saeb M. AdipoR1 and AdipoR2 gene expression are regulated by thyroid hormones in adipose tissue. Mol Cell Biochem 377: 55-63, 2013.

40. Seifi S, Tabandeh MR, Nazifi S, Saeb M, Shirian S, Sarkoohi P. Regulation of adiponectin gene expression in adipose tissue by thyroid hormones. J Physiol Biochem 68: 193-203, 2012.

41. Riis AL, Gravholt $\mathrm{CH}$, Djurhuus $\mathrm{CB}$, et al. Elevated regional lipolysis in hyperthyroidism. J Clin Endocrinol Metab 87: 47474753, 2002.

42. Germack R, Starzec A, Perret GY. Regulation of beta 1- and beta 3-adrenergic agonist-stimulated lipolytic response in hyperthyroid and hypothyroid rat white adipocytes. Br J Pharmacol 129: 448456, 2000.

43. Hsieh CJ, Wang PW. Serum concentrations of adiponectin in patients with hyperthyroidism before and after control of thyroid function. Endocr J 55: 489-494, 2008.

44. Chu CH, Lam HC, Lee JK, et al. Hyperthyroidism-associated insulin resistance is not mediated by adiponectin levels. J Thyroid Res 2011: 194721, 2011.

45. Komatsu M, Ohfusa H, Aizawa T, Hashizume K. Adiponectin inversely correlates with high sensitive C-reactive protein and triglycerides, but not with insulin sensitivity, in apparently healthy Japanese men. Endocr J 54: 553-558, 2007.

46. Hung YJ, Chu NF, Wang SC, et al. Correlation of plasma leptin and adiponectin with insulin sensitivity and beta-cell function in children - the Taipei Children Heart Study. Int J Clin Pract 60: 1582-1587, 2006. 
47. Hara K, Horikoshi M, Yamauchi T, et al. Measurement of the high-molecular weight form of adiponectin in plasma is useful for the prediction of insulin resistance and metabolic syndrome. Diabetes Care 29: 1357-1362, 2006.

48. Hulver MW, Saleh O, MacDonald KG, Pories WJ, Barakat HA Ethnic differences in adiponectin levels. Metabolism 53: 1-3, 2004.

49. Lithell H, Boberg J, Hellsing K, et al. Serum lipoprotein and apolipoprotein concentrations and tissue lipoprotein-lipase activity in overt and subclinical hypothyroidism: the effect of substitution therapy. Eur J Clin Invest 11: 3-10, 1981.

50. O'Brien T, Dinneen SF, O'Brien PC, Palumbo PJ. Hyperlipidemia in patients with primary and secondary hypothyroidism. Mayo Clin Proc 68: 860-866, 1993.

51. Hoppichler F, Sandholzer C, Moncayo R, Utermann G, Kraft HG. Thyroid hormone (fT4) reduces lipoprotein(a) plasma levels. Atherosclerosis 115: 65-71, 1995.

(C) 2015 The Japanese Society of Internal Medicine http://www.naika.or.jp/imonline/index.html 